\title{
Microstructure dependent fatigue crack growth in aged hardened aluminium alloys
}

\author{
L.P. Borrego ${ }^{a, *}$, J.M. Costa $^{\mathrm{b}}$, S. Silva ${ }^{\mathrm{b}}$, J.M. Ferreira ${ }^{\mathrm{b}}$ \\ ${ }^{a}$ Department of Mechanical Engineering, ISEC, Rua Pedro Nunes, Quinta da Nora, 3030-199 Coimbra, Portugal \\ ${ }^{\mathrm{b}}$ Department of Mechanical Engineering, University of Coimbra, Polo II, Pinhal de Marrocos, 3030-201 Coimbra, Portugal
}

Received 7 July 2003; received in revised form 5 April 2004; accepted 20 April 2004

\begin{abstract}
Fatigue crack propagation tests in constant amplitude loading, as well as with single peak overloads, have been performed in AlMgSi1-T6 aluminium alloys with different $\mathrm{Mn}$ and $\mathrm{Cr}$ contents. Crack closure was monitored in all tests by the compliance technique using a pin microgauge. A moderate stress ratio and a strong material dependence effects on the fatigue crack growth were observed. These effects are discussed in terms of the different dominant closure mechanism (plasticity-induced closure or roughness-induced closure). Roughness-induced closure dominates crack closure in the alloys with higher contents of $\mathrm{Mn}$ and $\mathrm{Cr}$ elements. In the alloy with a lower content of these elements, plasticity-induced closure is dominant. When roughness-induced closure is the prime pre-overload closure mechanism, the retardation effect is decreased in comparison to when plasticity-induced closure is dominant.
\end{abstract}

(C) 2004 Elsevier Ltd. All rights reserved.

Keywords: Aluminium alloys; Fatigue crack growth; Retardation; Microstructure; Crack closure; Overloads

\section{Introduction}

Age hardened aluminium alloys are of great technological importance. In particular for ground transport systems, when relatively high strength, good corrosion resistance and high toughness are required in conjunction with good formability and weldability, aluminium alloys with $\mathrm{Mg}$ and $\mathrm{Si}$ as alloying elements are used (Al-Mg-Si/6xxx series).

Crack closure has played a central role in the study of fatigue crack propagation [1]. A large number of research has made attempts to understand the influence of the mean stress on the fatigue crack growth rate based on the crack closure argument (e.g. [2,3]). Except for high stress ratios or high $\Delta K$ values, the fatigue crack growth can be affected more or less by the crack closure induced by plasticity in the two-parameter crack growth rate relation zone, Paris regime, or by oxidation and surface roughness in the near threshold regime. The influence of mean stress on the fatigue

\footnotetext{
${ }^{*}$ Corresponding author. Fax: +351-239790331.

E-mail address: borrego@isec.pt (L.P. Borrego).
}

crack growth rate has been explained with success by the crack closure using the normalised load parameter $U[3,4]$.

It is generally accepted that fatigue crack growth in the Paris regime is only weakly dependent on the materials microstructure when represented against $\Delta K_{\text {eff }}$ [5]. However, when $\mathrm{d} a / \mathrm{d} N$ is plotted against $\Delta K$, a number of examples of microstructure-dependent fatigue crack growth were reported in the literature (e.g. [5-7]). In a work of Bergner and Zouhar [6], crack growth rates of various aluminium alloys were observed to vary by a factor of about 20 at some values of $\Delta K$. They suggest the presence of material dependent effects of crack closure and environment to explain that discrepancies.

Constant amplitude fatigue crack growth in $\mathrm{Al}-\mathrm{Mg}-\mathrm{Si}$ alloys can be highly influenced by the dispersoid content due to $\mathrm{Mn}$ or Cr being present [8-10] as well as by the type of age hardening heat treatment $[6,7,10]$. In all cases, the crack growth behaviour depends mainly on whether an alloy presents plasticity-induced crack closure only, or additionally other retarding mechanisms such as roughness-induced closure [7-10]. 
Several mechanisms have been proposed to explain crack growth retardation following single peak tensile overloads, which include models based on residual stress [11], crack closure [3], crack tip blunting [12], strain hardening [13], crack branching [14] and reversed yielding [15]. However, the precise micromechanisms responsible for these phenomena are not fully understood.

The present paper analyses the influence of the dominant closure mechanism (plasticity-induced or roughness-induced) in constant- and variable-amplitude fatigue crack growth, using three $\mathrm{Al}-\mathrm{Mg}-\mathrm{Si}$ aluminium alloys with different $\mathrm{Mn}$ and $\mathrm{Cr}$ contents.

\section{Experimental procedure}

This research was conduced using AlMgSil (6082) aluminium alloys with a T6 heat treatment. The T6 treatment is a full heat treatment process comprising the operations of solution treatment, quenching and age-hardening. The alloys' chemical composition and mechanical properties are shown in Tables 1 and 2, respectively. The data presented in these tables are for the two alloys tested in this work (alloys B and C) and also for an alloy analysed in previous work (alloy A) $[16,17]$. These alloys differ mainly in the manganese and chromium contents.

Fatigue tests were undertaken, in agreement with ASTM E647 [18] standard, using middle-tension, $\mathrm{M}(\mathrm{T}), 3 \mathrm{~mm}$ (alloy A), $6 \mathrm{~mm}$ (alloy B) and $12 \mathrm{~mm}$ (alloy C) thick specimens. The specimens were obtained in the longitudinal transverse direction from a laminated plate. Fig. 1 illustrates the major dimensions of the samples used in the tests. The notch preparation was made by electrical-discharge machining. After that, the specimen surfaces were mechanically polished.

All experiments were performed in a servohydraulic, closed-loop mechanical test machine with $100 \mathrm{kN}$ capacity, interfaced to a computer for machine control and data acquisition. All tests were conducted in air and

Table 1

Chemical composition of the AlMgSil-T6 aluminium alloys [\% weight]

\begin{tabular}{llllllllll}
\hline Alloy & $\mathrm{Si}$ & $\mathrm{Mg}$ & $\mathrm{Mn}$ & $\mathrm{Fe}$ & $\mathrm{Cr}$ & $\mathrm{Cu}$ & $\mathrm{Zn}$ & $\mathrm{Ti}$ & Other \\
\hline $\mathrm{A}$ & 1.05 & 0.8 & 0.68 & 0.26 & 0.01 & 0.04 & 0.02 & 0.01 & 0.05 \\
$\mathrm{~B}$ & 0.98 & 1.08 & 0.90 & 0.32 & 0.25 & 0.07 & 0.15 & 0.1 & 0.15 \\
$\mathrm{C}$ & 1.28 & 1.13 & 0.90 & 0.49 & 0.30 & 0.09 & 0.2 & 0.1 & 0.15 \\
\hline
\end{tabular}

Table 2

Mechanical properties of the AlMgSi1-T6 alloys

\begin{tabular}{lllc}
\hline Alloy & $\begin{array}{l}\text { Tensile strength, } \\
\sigma_{\text {UTS }}[\mathrm{MPa}]\end{array}$ & $\begin{array}{l}\text { Yield strength, } \\
\sigma_{\text {YS }}[\mathrm{MPa}]\end{array}$ & $\begin{array}{l}\text { Elongation, } \\
\varepsilon_{\mathrm{r}}[\%]\end{array}$ \\
\hline A & $300 \pm 2.5$ & $245 \pm 2.7$ & 9 \\
B & $290 \pm 1.9$ & $250 \pm 2.4$ & 12 \\
C & 317 & 256 & 9.4 \\
\hline
\end{tabular}

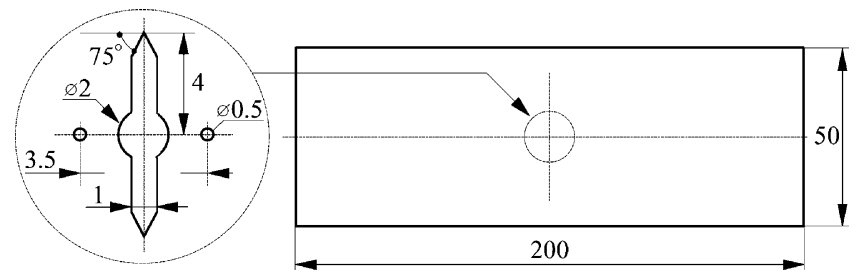

Fig. 1. Geometry of the $\mathrm{M}(\mathrm{T})$ specimen (dimensions in $\mathrm{mm}$ ).

room temperature, at a frequency of $20 \mathrm{~Hz}$ and a stress ratio of 0.05 or 0.25 . The specimens were clamped by hydraulic grips. The crack length was measured using a travelling microscope $(45 \times)$ with an accuracy of $10 \mu \mathrm{m}$. Collection of data was initiated after achieving an initial crack length $2 a_{0}$ of approximately $12 \mathrm{~mm}$.

The constant amplitude tests where performed in load control mode. The fatigue crack growth rate data were generated using the $\mathrm{K}$-increasing procedure for $\mathrm{d} a / \mathrm{d} N>1 \times 10^{-5} \mathrm{~mm} /$ cycle and the K-decreasing procedure for $\mathrm{d} a / \mathrm{d} N<1 \times 10^{-5} \mathrm{~mm} /$ cycle. Crack growth rates were determined by the incremental polynomial method using five consecutive points [18]. The single tensile overload tests were performed under constant $\Delta K$ and stress ratio $R$ conditions, by manually shedding the load with crack growth. The load shedding intervals were chosen so that the maximum $\Delta K$ baseline level, $\Delta K_{\mathrm{BL}}$, variation was smaller than $2 \%$. The overloads were applied under load control mode during one cycle by programming the increase in load to the designated overload value.

After overloading, the baseline loading was resumed and the transient crack growth behaviour associated with the overload was carefully observed. The influence of single peak tensile overloads was investigated at two different stress ratios, $R=0.05$ and $R=0.25$. The overloads were applied at $\Delta K$ baseline levels of 8 and $12 \mathrm{MPa} \mathrm{m}{ }^{1 / 2}$, with overload ratios OLR of 2 and 2.5. OLR was defined as

$\mathrm{OLR}=\frac{\Delta K_{\mathrm{OL}}}{\Delta K_{\mathrm{BL}}}=\frac{K_{\mathrm{OL}}-K_{\min }}{K_{\max }-K_{\min }}$

where $K_{\max }, K_{\min }$, and $K_{\mathrm{OL}}$ are the maximum, minimum, and peak overload intensity factors, respectively. The crack growth rates were determined by the secant method [18].

Load-displacement behaviour was monitored at specific intervals throughout each of the tests using a pin microgauge elaborated from a high sensitive commercial axial extensometer $( \pm 0.625 \mathrm{~mm}$ of maximum displacement), as illustrated in Fig. 2. The gauge pins were placed in two drilled holes of $0.5 \mathrm{~mm}$ diameter located above and below the centre of the notch (Fig. 2). The distance between these holes was $3.5 \mathrm{~mm}$. In order to collect as many load-displacement data as possible during a particular cycle, the frequency was reduced to $0.5 \mathrm{~Hz}$. Noise on the strain gauge 

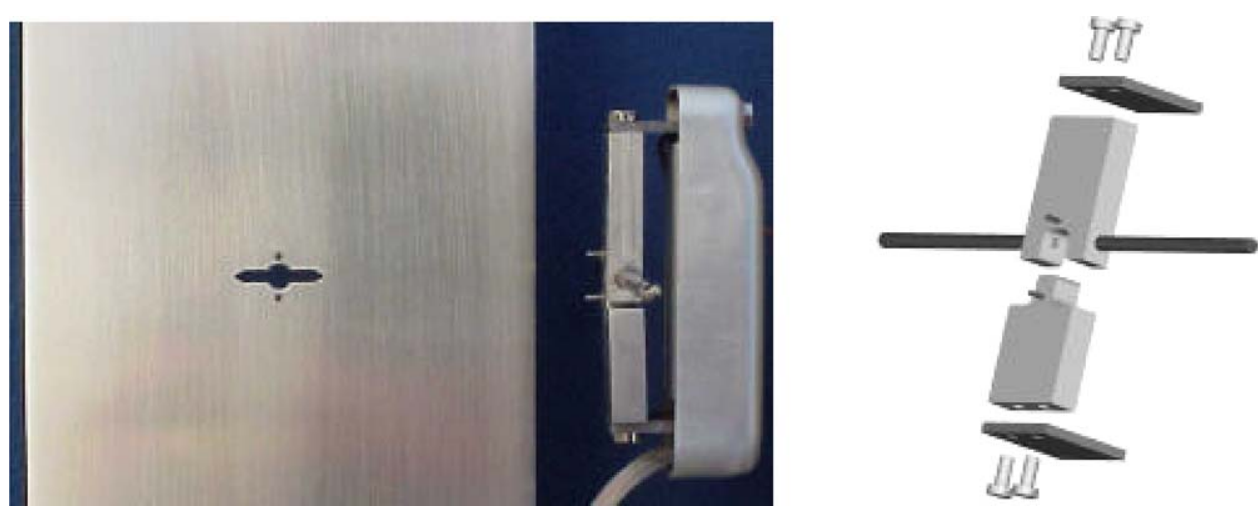

Fig. 2. Pin microgauge and corresponding position in the specimen.

output was reduced by passing the signal through a 1 $\mathrm{Hz}$ low-pass mathematical filter.

Fig. 3 illustrates the typical load-displacement records obtained in this study. Variations of the opening load, $P_{\mathrm{op}}$, were derived from these records using the technique known as maximisation of the correlation coefficient [19]. This technique involves taking the upper $10 \%$ of the $P-\varepsilon$ data and calculating the least squares correlation coefficient. The next data pair is then added and the correlation coefficient is again computed. This procedure is repeated for the whole data set. The point at which the correlation coefficient reaches a maximum can then be defined as $P_{\text {op }}$.

The fraction of the load cycle for which the crack remains fully open, parameter $U$, was calculated by the following equation:

$U=\frac{P_{\max }-P_{\mathrm{op}}}{P_{\max }-P_{\min }}$

where $P_{\max }, P_{\min }$, and $P_{\text {op }}$ are the maximum, mini-

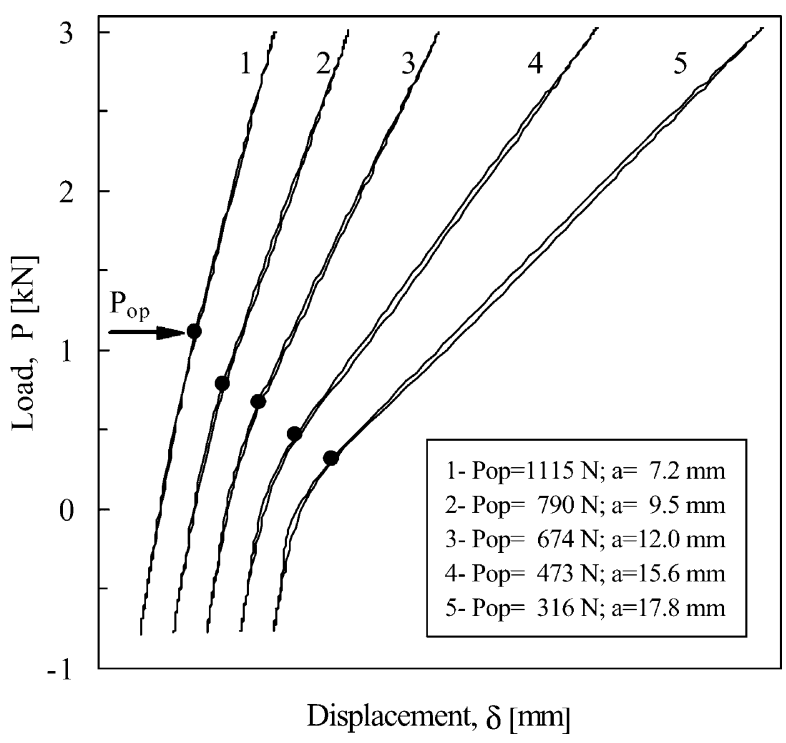

Fig. 3. Typical load-displacement records for alloy A. mum, and crack opening loads, respectively. The values of the effective stress intensity factor range parameter, $\Delta K_{\text {eff, }}$, were than calculated by the expression:

$\Delta K_{\mathrm{eff}}=K_{\mathrm{max}}-K_{\mathrm{op}}=U \Delta K$

where $K_{\text {op }}$ is the stress intensity factor at opening load.

The accuracy of the all processes used to obtain the crack closure level was evaluated. At the same time, the sensitivity of pin gauge location with respect to the crack tip was also analysed. The pin gauge was put at different positions in order to explore how it would affect the crack opening results. The pin gauge was placed at the centre line of the specimen, at $3 \mathrm{~mm}$ behind the crack tip, and at $1 \mathrm{~mm}$ behind the crack tip. Three load-displacement records were obtained for each position of the pin gauge. The values of $P_{\mathrm{op}}$ and parameter $U$ measured in alloy A at a crack length of $20 \mathrm{~mm}$ and $\Delta K=9 \mathrm{MPa} \mathrm{m}^{1 / 2}$ are presented in Table 3 .

Table 3 shows that the variation of opening load values obtained at different pin gauge locations is less than $2.7 \%$, corresponding to a change in parameter $U$ lower than $0.7 \%$. When the distance to the crack tip is increased, a small increase of scattering is observed. However, for each pin gauge location, the variation of $P_{\text {op }}$ values is always less than $3.8 \%$, which represents a change in parameter $U$ lower than $1 \%$. Therefore, the results presented in Table 3 clearly show that the crack closure values are fairly accurate and at the same time, for distances higher than $1 \mathrm{~mm}$, practically independent of the pin gauge location relatively to the crack tip.

The fatigued fracture surfaces of specimens were observed in a Philips XL30 scanning electron microscope. The fracture surface profile and roughness at different distances from the specimen surfaces were also evaluated. The laser equipment Mahr RM600-3D was used for these measurements. The optical distance sensor works with an infrared laser whose beam is focused on the surface of the sample. The size of the spot is $1 \mu \mathrm{m}$ and the resolution of the equipment is $0.01 \mu \mathrm{m}$. The geometry of the surface of fatigue specimens was determined through analysis of 
Table 3

Scattering of crack closure measurements and influence of pin gauge location

\begin{tabular}{|c|c|c|c|c|c|c|}
\hline \multirow[t]{3}{*}{ Measurement } & \multicolumn{6}{|c|}{ Pin gauge location } \\
\hline & \multicolumn{2}{|c|}{ Centre line } & \multicolumn{2}{|c|}{$3 \mathrm{~mm}$ behind crack tip } & \multicolumn{2}{|c|}{$1 \mathrm{~mm}$ behind crack tip } \\
\hline & $P_{\mathrm{op}}[\mathrm{N}]$ & $U[-]$ & $P_{\mathrm{op}}[\mathrm{N}]$ & $U[-]$ & $P_{\mathrm{op}}[\mathrm{N}]$ & $U[-]$ \\
\hline 1 & 1740 & 0.835 & 1701 & 0.840 & 1774 & 0.831 \\
\hline 2 & 1820 & 0.825 & 1709 & 0.839 & 1762 & 0.832 \\
\hline 3 & 1686 & 0.842 & 1813 & 0.826 & 1831 & 0.824 \\
\hline Mean & 1749 & 0.834 & 1741 & 0.835 & 1789 & 0.829 \\
\hline Standard deviation & 68 & 0.008 & 62 & 0.008 & 37 & 0.005 \\
\hline
\end{tabular}

profiles of the fracture surface, parallel to the main crack propagation direction.

\section{Results}

\subsection{Constant amplitude loading}

The influence of the stress ratio on the fatigue crack growth rate for alloys $\mathrm{B}$ and $\mathrm{C}$, with thickness of 6 and $12 \mathrm{~mm}$, respectively, can be seen in Fig. 4. A moderate $R$-ratio effect on the fatigue crack growth rate was observed. The crack growth rate $\mathrm{d} a / \mathrm{d} N$ increases with $R$. A similar trend was observed in alloy $\mathrm{A}$ as reported elsewhere [16].

Fig. 5 compares the results for alloy $\mathrm{B}$ at the stress ratio of $R=0.05$ with data for alloy A obtained in a previous work [16] and the results obtained by Shercliff and Fleck [20] also for an AlMgSil-T6 alloy. These authors used $\mathrm{M}(\mathrm{T})$ and bending specimens with a

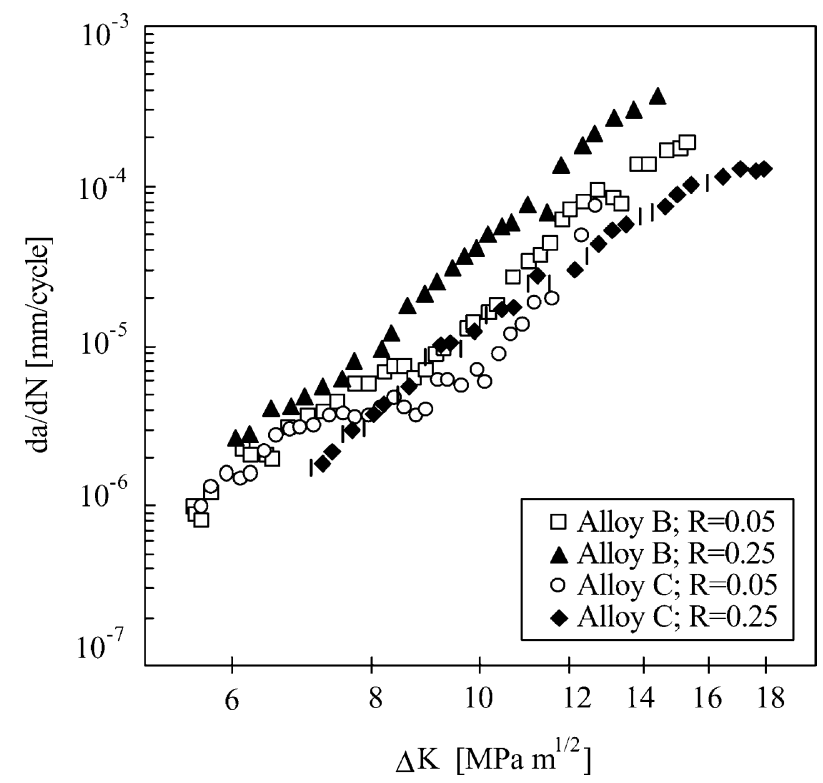

Fig. 4. Effect of stress ratio on fatigue crack growth rate for alloys $\mathrm{B}$ and $\mathrm{C}$. thickness of $9.9 \mathrm{~mm}$, unfortunately no effective chemical composition was given. This figure shows that crack growth rates for alloy B are significantly lower than that for alloy A, and even lower than the ones obtained in $[20]$.

The different specimen thickness cannot explain this behaviour, because for higher thicknesses plane strain prevails. The plasticity-induced closure level in plane strain tends to be lower than in plane stress [21] and consequently $\mathrm{d} a / \mathrm{d} N$ increases as experimentally observed in steels [22] and aluminium alloys [23,24].

As fatigue crack growth rate has shown material and stress ratio dependence, a crack closure analysis was carried out to correlate the results with $\Delta K_{\text {eff. }}$ Fig. 6 presents the variation of the normalised load ratio parameter $U$ as a function of $\Delta K$ for alloys $\mathrm{B}$ and $\mathrm{C}$. The parameter $U$ decreases with decreasing $\Delta K$. However,

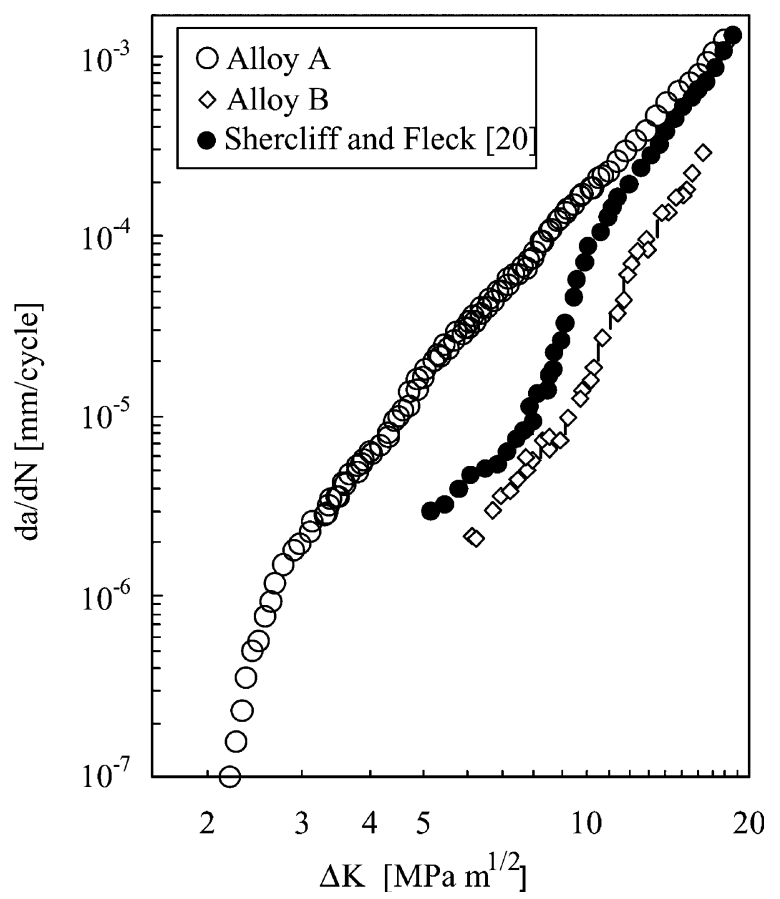

Fig. 5. Fatigue crack growth rates for different AlMgSi1-T6 aluminium alloys at $R=0.05$. 


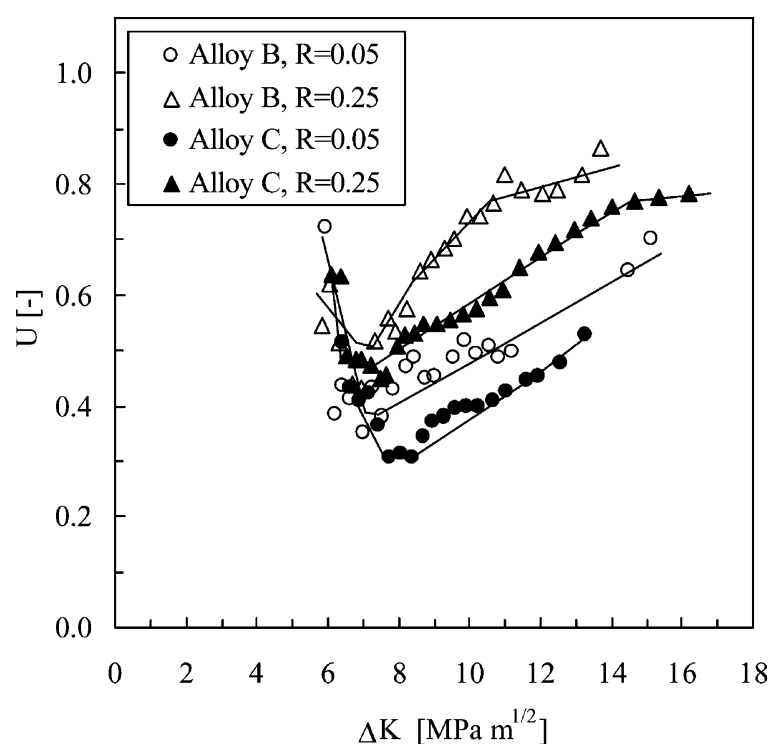

Fig. 6. Influence of the stress ratio on the crack closure level for alloys B and C.

for $\Delta K$ values lower than approximately $6.5 \mathrm{MPa} \mathrm{m}^{1 / 2}$, $U$ dropped steeply with increasing $\Delta K$. This behaviour only occurs for small crack lengths during the early period of the fatigue tests. It can be explained by the great crack length dependence of roughness-induced crack closure, during the transition from mechanical small cracks to long cracks [25]. The values of $U$ increased with the stress ratio and for the same $R$, alloy $\mathrm{C}$ presents a closure level higher than alloy B.

Fig. 7 presents the variation of $K_{\mathrm{op}} / K_{\max }$ as a function of $\Delta K$ for alloys $\mathrm{A}$ and $\mathrm{B}$ at $R=0.05$. Once again the results obtained by Shercliff and Fleck [20] are shown for comparison. This figure shows that the crack closure data are in accordance with the observed variation in the crack growth rates presented in Fig. 5, i.e., higher closure levels for lower $\mathrm{d} a / \mathrm{d} N$ values.

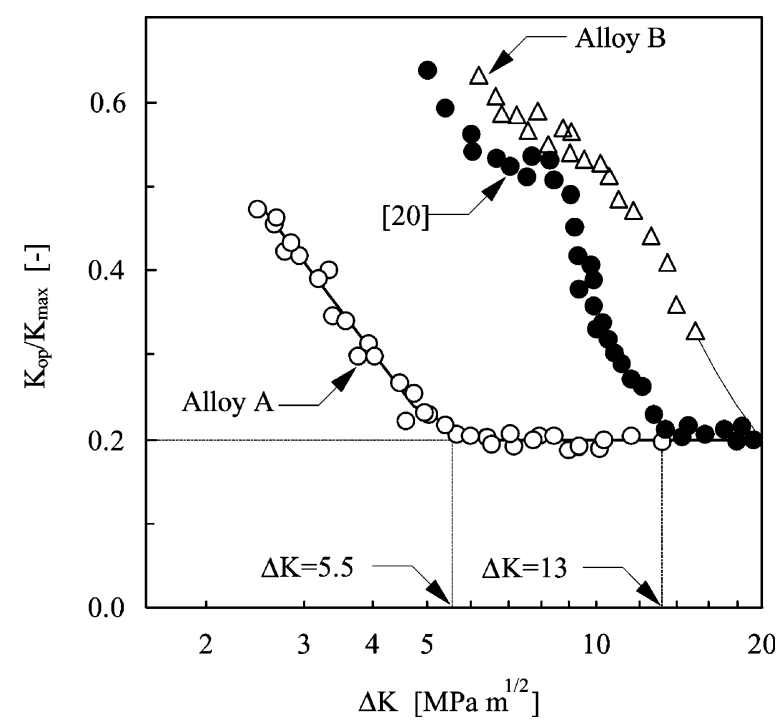

Fig. 7. Crack closure data for AlMgSi1-T6 Alloys. $R=0.05$.

Fig. 7 also shows that in general $K_{\mathrm{op}} / K_{\max }$ decreases steeply as $\Delta K$ increases until a minimum $K_{\text {op }} / K_{\max }$ value of approximately 0.2 is attained, after which this ratio remains basically constant. For alloy A and for the data presented in [20], the constant $K_{\text {op }} / K_{\max }$ ratio is achieved at $\Delta K=5.5 \mathrm{MPa} \mathrm{m}^{1 / 2}$ and $\Delta K=$ $13 \mathrm{MPa} \mathrm{m}{ }^{1 / 2}$, respectively. For higher values of $\Delta K$, closure values are generally independent of $\Delta K$. For alloy $\mathrm{B}$, this condition was not attained. From the trend of the curve for this alloy, $K_{\mathrm{op}} / K_{\max }=0.2$ is estimated to occur only after $\Delta K=20 \mathrm{MPa} \mathrm{m} \mathrm{m}^{1 / 2}$.

Images of typical crack paths viewed from the side face of M(T) specimens tested at $R=0.05$ for the three alloys are compared in Fig. 8(a). The respective images of the fatigued fracture surface of each alloy are shown in Fig. 8(b). In these figures, the crack growth direction is from right to left. It can be clearly seen that alloys B and $\mathrm{C}$ have a considerably more irregular crack path (a)

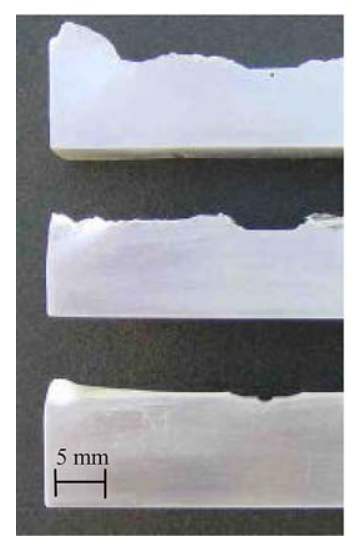

(b)

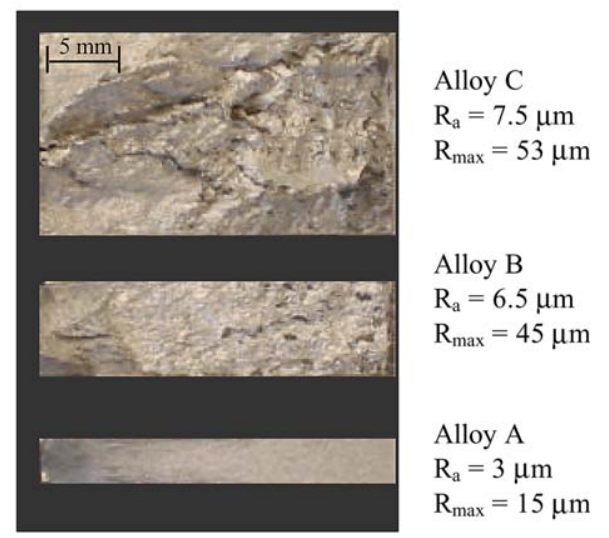

Fig. 8. Images of specimens: (a) typical crack paths; (b) fatigued fracture surfaces. 
and surface topography than alloy A. The surface roughness of the fatigued fracture surfaces was also evaluated. $R_{\mathrm{a}}$ and $R_{\max }$ are the roughness parameters used to assess the fatigued surface topography. The parameter $R_{\mathrm{a}}$ is the roughness average, i.e., the arithmetic average of the absolute values of the roughness profile ordinates and $R_{\max }$ is the largest single peakto-valley height within five adjoining sample lengths. The values of $R_{\mathrm{a}}$ and $R_{\max }$ superimposed in Fig. 8 are mean values of at least five measurements.

Although the roughness is characterised by a significant scatter, alloy $\mathrm{C}$ presented a relative higher roughness in comparison to alloy B. Furthermore, these measurements showed that for alloys $\mathrm{B}$ and $\mathrm{C}$ the mean values of $R_{\mathrm{a}}$ and $R_{\max }$ were at least 2 and 3 times higher, respectively, in comparison to alloy A, suggesting an effect of roughness in the high crack closure level observed for these alloys.

Fig. 9 shows the $\mathrm{d} a / \mathrm{d} N-\Delta K_{\text {eff }}$ data for alloys B and $\mathrm{C}$ at the two analysed stress ratios $R=0.05$ and $R=0.25$. The $\mathrm{d} a / \mathrm{d} N-\Delta K_{\text {eff }}$ curves obtained in previous work [16] and by Shercliff and Fleck [20] are also plotted for comparison. This figure shows for alloy $\mathrm{C}$ (alloy with higher $\mathrm{Mn}$ and $\mathrm{Cr}$ contends), mainly above $\mathrm{d} a / \mathrm{d} N>3 \times 10^{-5}$, an anomalous behaviour of the data points for $R=0.05$ which are on the left of those for $R=0.25$. This behaviour was already observed in Fig. 4 where also in the $\mathrm{d} a / \mathrm{d} N$ versus $\Delta K$ representation and above $\mathrm{d} a / \mathrm{d} N>3 \times 10^{-5}$, the data points for $R=0.05$ are on the left of those obtained at $R=0.25$. The conversion of $\Delta K$ in $\Delta K_{\text {eff }}$ through the correction of crack closure only emphasises this behaviour. It is important to notice that alloy $\mathrm{C}$ specimens

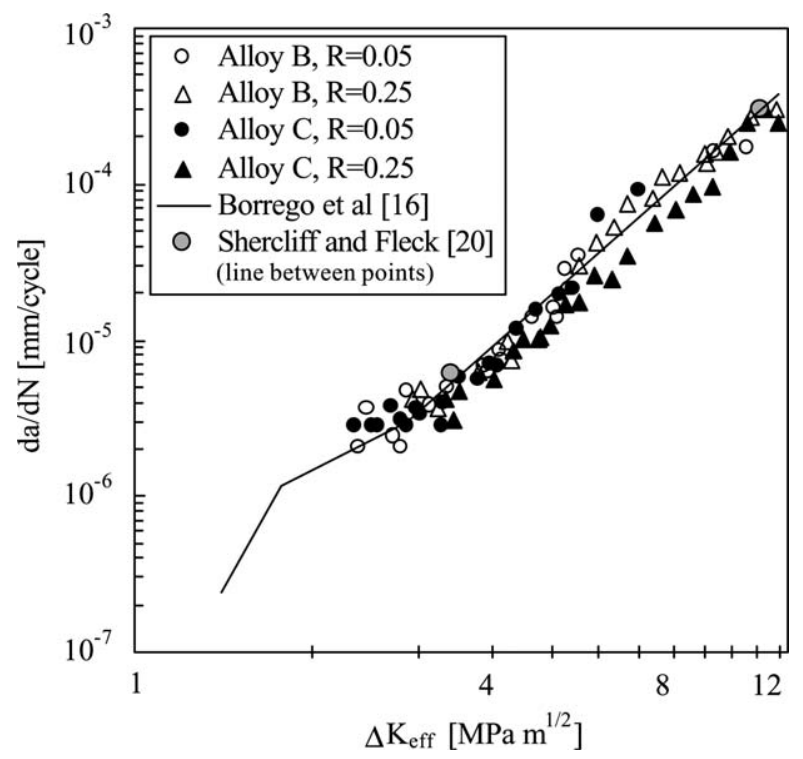

Fig. 9. Fatigue crack growth rate versus $\Delta K_{\text {eff }}$ for AlMgSil-T6 alloys. are thicker $(12 \mathrm{~mm})$ than those of alloys $\mathrm{A}$ and $\mathrm{B}$ and that the crack path observed in alloy $\mathrm{C}$ is very tortuous. Therefore, the more plausible explanation of this anomalous behaviour and of the lower correlation obtained through $\Delta K_{\text {eff }}$ for alloy $\mathrm{C}$ is that the $\mathrm{d} a / \mathrm{d} N$ values measured at the surface of the specimen of this alloy probably do not correspond to the real mean crack growth rate verified in the all crack front.

In any case, the fatigue crack growth rate data tend to fall within an acceptable scatter band when $\mathrm{d} a / \mathrm{d} N$ is plotted against $\Delta K_{\text {eff }}$ compared to Fig. 4. Furthermore, this scatter band is in fairly agreement with the $\mathrm{d} a / \mathrm{d} N-\Delta K_{\text {eff }}$ relationship determined in previous work for alloy $\mathrm{A}(R=0.25,0.05,0.25$ and 0.4$)[16]$ as well as the results presented by Shercliff and Fleck [20]. Therefore, the crack closure effect can generally correlate well the influence of the stress ratio $R$ and also of the microstructure.

\subsection{Single peak overload}

The normalised crack growth rate, $(\mathrm{d} a / \mathrm{d} N) /$ $(\mathrm{d} a / \mathrm{d} N)_{\mathrm{CA}}$, where $(\mathrm{d} a / \mathrm{d} N)_{\mathrm{CA}}$ is the constant amplitude crack growth rate corresponding to the baseline level, following a $100 \%$ single tensile overload $(\mathrm{OLR}=2)$ applied at $\Delta K_{\mathrm{BL}}=8 \mathrm{MPa} \mathrm{m}{ }^{1 / 2}$ can be seen in Fig. 10. In this figure, the normalised crack growth rate is plotted against the crack length from the overload event, $a-a_{\mathrm{OL}}$, where $a_{\mathrm{OL}}$ is the crack length at which the overload is applied.

Fig. 10 shows that for alloy A, there is a brief initial acceleration of crack growth rate immediately after the overload. The subsequent crack growth rate decreases until its minimum value is reached, followed by a gradual approach to the level of the baseline steady state.

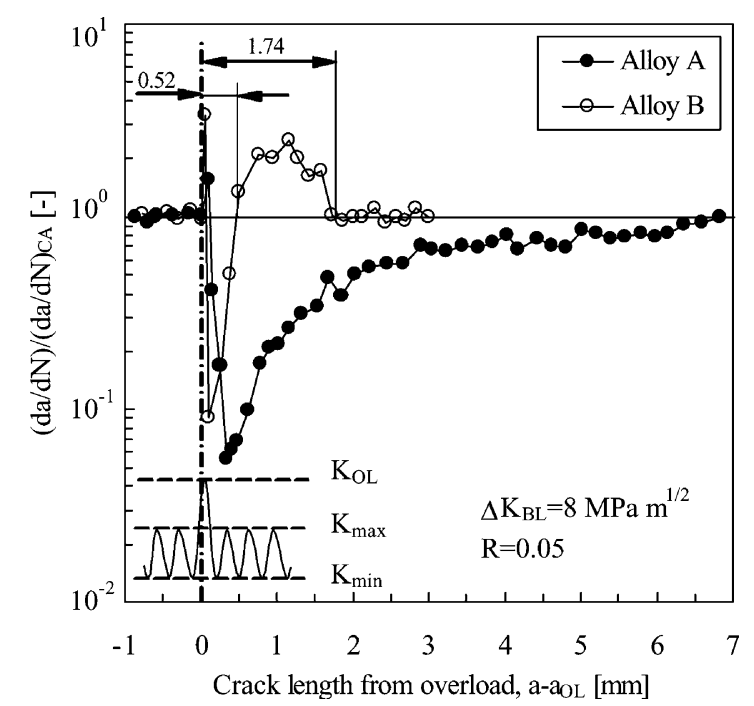

Fig. 10. Transient crack growth rate following a single tensile overload. 
The crack growth transients in alloy A are in accordance with the behaviour usually referred to as delayed retardation of crack growth [26-28] typically observed for this alloy $[16,17,26]$. Alloy B presents mainly an immediate retardation, followed by an increase in the crack growth rate until a maximum value higher than the pre-overload $\mathrm{d} a / \mathrm{d} N$ value is reached. Only then does the crack growth rate gradually approach the level of the baseline steady state. In this alloy, the initial brief acceleration is only due to the overload cycle itself. Moreover, the overload retardation effect is much higher in alloy $\mathrm{A}$ than in alloy $\mathrm{B}$, retardation during approximately $a-a_{\mathrm{OL}}=7 \mathrm{~mm}$ for alloy $\mathrm{A}$, while during only $0.52 \mathrm{~mm}$ for alloy B.

The corresponding crack closure response is presented in Fig. 11. The obtained data are plotted in terms of the normalised load ratio parameter $U$, calculated by Eq. (2), against the crack growth increment from the point of overload application.

Prior to the overload, the $U$ parameter at the baseline loading level is relatively stable. For alloy A, upon application of the overload, $U$ rapidly increases followed by a decrease to a minimum value and then increases gradually towards the corresponding value of the baseline level. It is important to notice that the decrease in $U$ is not immediate after the overload application, but on the contrary, decreases slowly towards the minimum value. This is in accordance with delayed retardation behaviour observed on the crack growth transients of this alloy. However, the pre-overload value is not attained at least until a crack increment after overloading greater than the retardation period is reached. This fact is attributed to the discontinuous closure or partial closure phenomenon generally seen in

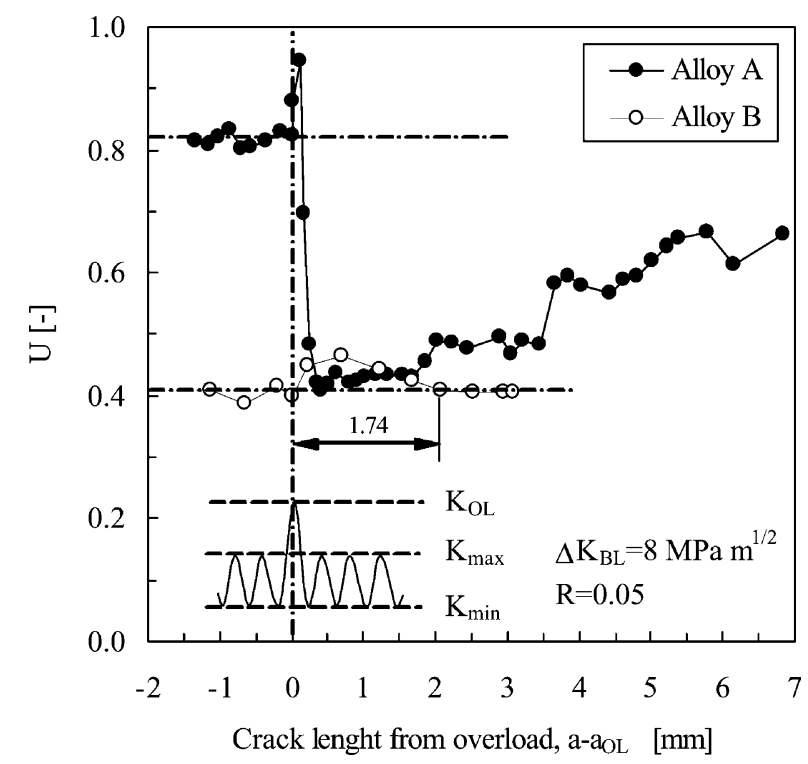

Fig. 11. Crack closure response following a single tensile overload. this alloy $[16,17]$. According to this phenomenon, first identified experimentally by Fleck [28], the crack is open near the tip, but still shut near the overload location at loads below the crack opening load, inducing measurements of crack opening loads that are excessively high.

In contrast, the closure transients for alloy B are quite different from the corresponding crack growth rate trend. Upon application of the overload, the crack closure level in alloy B shows no increase, as initially could be anticipated by the crack growth rate transients, presenting even a small reduction until the corresponding value of the baseline level is reached at $a-a_{\mathrm{OL}}=1.74 \mathrm{~mm}$. Alloy $\mathrm{C}$ basically shows the same crack growth transients and crack closure level trends as observed for alloy B.

\subsection{Fractography}

Figs. 12(a)-(f) show some typical features of the fatigue fracture surfaces of alloys $\mathrm{A}$ and $\mathrm{C}$ to highlight differences between the fatigue surfaces of the alloys. The images presented were obtained at the position close to the centre of the specimens. Low magnification images of alloys A and C are shown in Figs. 12(a) and (b), respectively. High magnification images of these regions are presented in Figs. 12(c) and (d). Finally, Figs. 12(e) and (f) illustrate some details of the fatigue fracture surfaces of alloys $\mathrm{A}$ and $\mathrm{C}$, respectively. The crack growth direction is from bottom to top in the surface images of alloy A and from left to right in the images corresponding to alloy $\mathrm{C}$.

It can be clearly seen, by comparison between Figs. 12(a) and (b), that alloy $\mathrm{C}$ has a surface topography much more irregular than alloy A. Typical fatigue fracture surfaces of alloy A have a relatively chaotic wavy appearance and the fracture path did not seem the result from a single mechanism of fracture (see Fig. 12(c)). The crack propagates on multiple plateaus that are at different elevations with respect to each other. The plateaus (labelled A) are joined either by tear ridges or walls (labelled B). These relatively smooth areas consisted predominantly of transgranular fatigue propagation containing fairly well-developed striations with evidence of some secondary cracking and widely dispersed microvoid formation around second-phase particles (labelled C). Fig. 12(e) illustrates the occurrence of cleaved particles observed in many voids (arrows). These observations are consistent with those reported for similar alloys $[29,30]$.

The orientation of striation alignment generally differs from patch to patch as clearly observed in Fig. 12(c). Therefore, the crack front is probably not a straight line, actually it can be quite a tortuous line, and some dispersion of the crack rate along the crack front must be expected. For lower $\Delta K$ values, the 

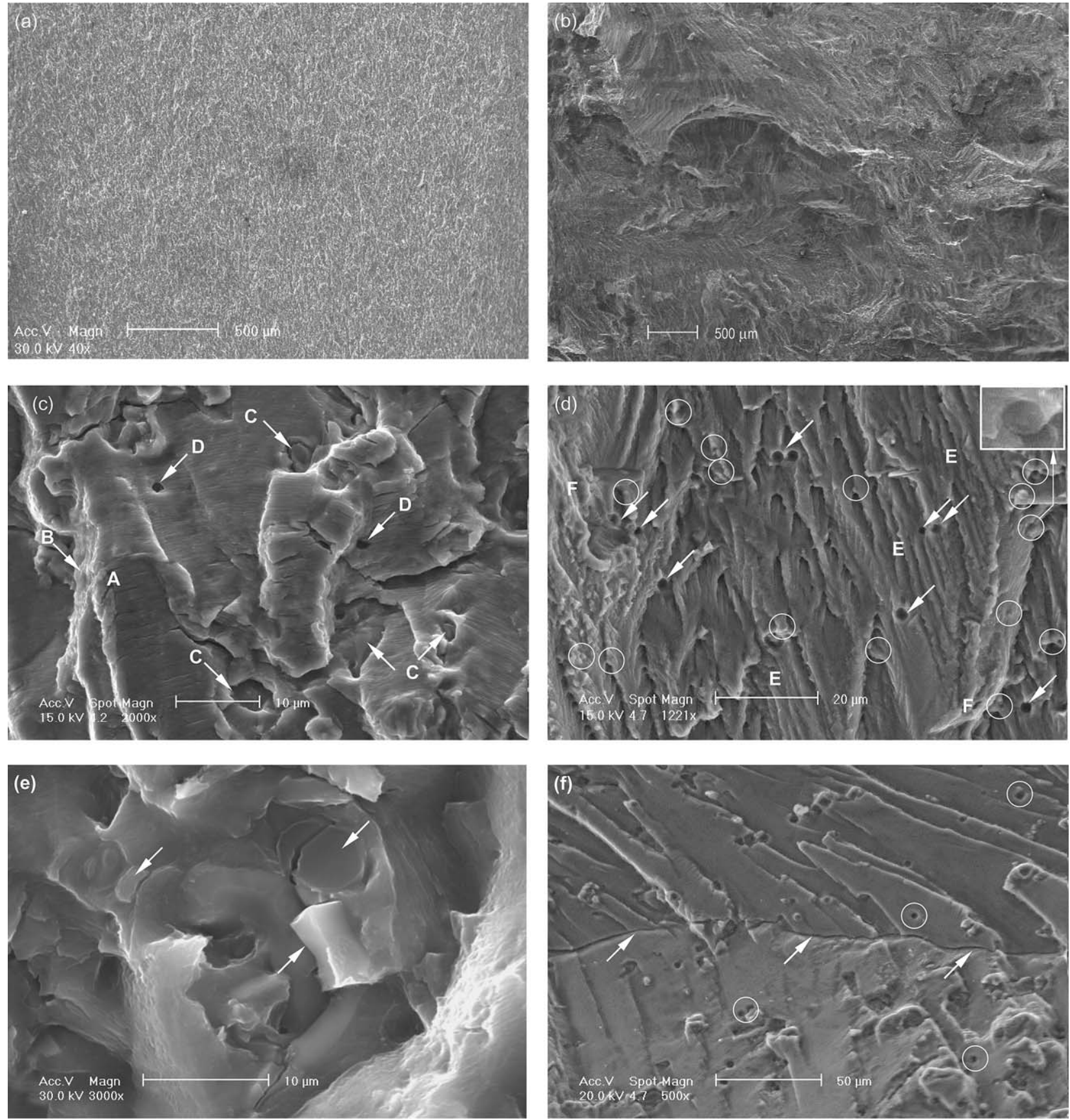

Fig. 12. SEM images of fracture surfaces. Low magnification images at $R=0.05$ : (a) alloy A; (b) alloy C. High magnification images: (c) alloy A, $R=0.05, \Delta K=12 \mathrm{MPa} \mathrm{m}^{1 / 2}, \mathrm{~d} a / \mathrm{d} N=3.2 \times 10^{-4} \mathrm{~mm} /$ cycle; (d) alloy $\mathrm{C}, R=0.05, \Delta K=9 \mathrm{MPa} \mathrm{m} / 2, \mathrm{~d} a / \mathrm{d} N=4.9 \times 10^{-6} \mathrm{~mm} / \mathrm{cycle}^{1 / 2}$ (e) detail of (c) showing broken particles in voids; (f) twist boundary in alloy $\mathrm{C}, R=0.25, \Delta K=9.7 \mathrm{MPa} \mathrm{m}^{1 / 2}, \mathrm{~d} a / \mathrm{d} N=1.9 \times 10^{-5} \mathrm{~mm} / \mathrm{cycle}$.

fatigue striations were poorly defined and occupied a less portion of the fatigue surface. Furthermore, secondary cracking was practically absent.

In contrast, the fatigue fracture surface of alloy $\mathrm{C}$ (Fig. 12(d)) exhibits a more brittle nature, i.e., cleavagelike fracture, as suggested by the presence of a high number of cleavage steps (labelled E). Evidence of some ductile tearing (labelled F) was also observed. This alloy showed many unbroken particles at the fracture surface (marked by rings in Fig. 12(d)). These particles, highlighted by the magnification image at the top right corner of Fig. 12(d), are spherical shaped Mn/Cr-rich dispersoids with diameters between 0.5 and $2.5 \mu \mathrm{m}$. The dispersoid particles are separated from the matrix forming microvoids at the matting fatigue fracture surface as signalised by the arrows in Fig. 12(d). The presence of these microvoids, although in a much lower density, was also observed at the fracture surface of alloy A (labelled 
with D in Fig. 12(c)). The typical fracture surface of alloy B exhibited similar features as alloy $\mathrm{C}$, with a small decreased amount of incoherent dispersoid particles and associated microvoid formation.

Fig. 12(f) shows a distinct cleavage pattern on the fatigue fracture surface of alloy $\mathrm{C}$ generally referred to as twist boundary [30]. The intergranular fracture along the grain or subgrain boundary (arrows) is accompanied by a small rotation of the cleavage planes about an axis perpendicular to the boundary. Because of the significant misalignment of cleavage planes at the boundary, the cleavage steps do not cross but reinitiate at the boundary as a series of new parallel cleavage steps [30]. A significant density of microvoids formed from round dispersoid particles is also clearly seen in this figure (some of them marked by rings).

\section{Discussion}

In the work of Bergner et al. [7], aluminium alloys were classified in two distinct groups. One of the groups (denoted "I") is characterised by approximately equal crack growth rates at $\Delta K_{0}=10 \mathrm{MPa} \mathrm{m}{ }^{1 / 2}$, of about $(1.65 \pm 0.45) \times 10^{-4} \mathrm{~mm} /$ cycle. In contrast, the other group (denoted "II") is characterised by varying $\mathrm{d} a / \mathrm{d} N$ at $\Delta K_{0}$. Crack growth rates of group II are always lower than those observed for group I. They propose that the main criterion of differentiation between the alloys of groups I and II is whether an alloy shows, respectively, plasticity-induced closure only or additionally other retarding mechanisms such as roughness-induced closure.

Due to the higher degree of coherency of the main strengthening precipitates with the aluminium lattice for naturally aged conditions, they are mainly sheared by dislocations promoting planar slip conducing to a higher roughness due to an extensive crack deflection. Therefore, the naturally aged aluminium alloys are classified in group II [7]. Artificially aged conditions such as T6, having a lower coherency of its precipitates with the aluminium lattice, a lower crack deflection and roughness are expected because a significant fraction of precipitates are looped or bypassed. Thus, they are included in group I [7].

Fig. 5 shows that while alloy A, being in artificially aged condition T6, is in agreement of the above statements, as it presents a crack growth rate of approximately $1.69 \times 10^{-4} \mathrm{~mm} /$ cycle at $\Delta K_{0}=10 \mathrm{MPa} \mathrm{m}^{1 / 2}$. Alloys $\mathrm{B}$ and $\mathrm{C}$, although being in the same $\mathrm{T} 6$ condition, have significantly lower values of $\mathrm{d} a / \mathrm{d} N$ at $\Delta K_{0}$, approximately $1.5 \times 10^{-5}$ and $7.5 \times 10^{-6} \mathrm{~mm} /$ cycle, respectively, being better included in group II.

The basic distinction between the alloys analysed in this work is the amount of $\mathrm{Mn}$ and $\mathrm{Cr}$ added as dispersoid-forming elements. As observed in Fig. 12, the higher content of these elements in alloys B and C lead to an higher amount of rich $\mathrm{Mn} / \mathrm{Cr}$ dispersoid particles relatively to alloy A. Although some influence of the age hardening heat treatment cannot be discharge, the lower crack growth rates observed for alloys B and C can be mainly attributed to the higher dispersoid contend in these alloys. The dispersoid phase is composed by spherical and rod shaped particles, rich in $\mathrm{Mn}$ and containing other alloying elements such as $\mathrm{Si}$ and $\mathrm{Cr}$, dispersed uniformly in the matrix [10]. This phase promotes planar slip and large deviations of the crack from the average crack growth direction $[9,10]$ resulting in a tortuous crack path and higher roughness of the fatigued fracture surface as indeed observed in Fig. 8. This effect enhances roughness-induced crack closure and, thus, improves the fatigue properties $[9,10]$.

The crack closure data depicted in Fig. 7 show that the crack closure level in alloy A only decreases with increasing stress intensity range until $\Delta K=$ 5.5 $\mathrm{MPa} \mathrm{m}{ }^{1 / 2}$, after which remains basically constant. Such behaviour is attributed to the generally accepted dominance of oxide-induced and roughness-induced crack closure in the near threshold regime. In the Paris regime, plasticity-induced crack closure dominates and closure values are generally independent of $\Delta K$. In contrast, the crack closure levels in alloys $\mathrm{B}$ and $\mathrm{C}$ decrease with increasing $\Delta K$ for almost all $\Delta K$ values. Such behaviour is associated to the dominance of roughness-induced crack closure in all the range of $\Delta K$. Furthermore, the higher Paris exponent observed for alloys $\mathrm{B}$ and $\mathrm{C}$ in Figs. 4 and 5 is consistent with a relatively decreasing contribution of roughness-induced crack closure with increasing $\Delta K$ in comparison with plasticity-induced crack closure.

Therefore, it is suggested that distinct closure mechanisms must exist in the alloys. For alloy A, plasticity- and roughness-induced crack closures must be present, being the last significant only near threshold. For the other alloys, roughness-induced closure must also be dominate in the Paris regime.

The phenomenon of plasticity-induced closure seems to be the main cause of the post-overload crack growth transients for alloy A depicted in Fig. 10. The overload cycle induces crack tip blunting, which tends to remove near tip closure and reduces far field closure. Consequently, the crack closure level is reduced to the value prior to the overload increasing the effective stress intensity $\Delta K_{\text {eff }}$ and, thus, leading to the brief initial crack acceleration $[27,28]$. As the crack grows into the compressive residual stress field formed by the overload cycle, it encounters increased levels of plasticity that induce near tip crack closure. This results in a gradual increase of the closure level (see Fig. 11), which implies a gradual reduction of $\Delta K_{\text {eff }}$ and therefore of the crack growth rate. As the crack grows outside the zone of 
largest plastic deformations, the crack closure level and, hence, $\mathrm{d} a / \mathrm{d} N$ gradually approach the values corresponding to the baseline level. However, there is some discrepancy between the crack growth rate transients and the corresponding crack closure trend presented in Figs. 10 and 11, respectively. This disagreement is due, as already mentioned, to the discontinuous closure or partial closure phenomenon.

Recently, Paris et al. [31] and Donald and Paris [32] introduced the new concept of partial closure. According to this concept, a significant contribution to fatigue damage occurs in the load range below the opening load when measured remotely from the crack tip by the compliance technique. Considering that even those who have questioned the assumption of plasticity-induced closure [33] do not object to crack surface interference caused by mismatched roughness, they proposed the partial closure model. This model suggests that an approximate result of the effective range of $K$, between its real minimum and maximum, could be given by the following simple expression:

$\Delta K_{\text {eff }}=K_{\text {max }}-\frac{2}{\pi} K_{\text {op }}$

Experimental results showed that, for several aluminium alloys, this equation produces very good correlation of fatigue crack growth data under loadreduction (threshold) simulations [31,32]. Incidentally, Newman [34] has also indicated that under conditions of remote (partial) closure, the appropriate opening stress to calculate the effective stress is $0.62 \sigma_{\mathrm{op}}$, which is very close to $2 / \pi \sigma_{\mathrm{op}}$.

It is important to note that the partial closure model was physically established assuming that, under $\Delta K$ reduction simulations, the crack is open at tip and closed near the load reduction location, at loads below the crack opening load [31]. This is similar to the hypothesis of the discontinuous closure phenomenon for overload conditions [28]. Previous work [17] performed a detailed analysis of the effect of single overloads applied in alloy $A$ with several overload intensities, stress ratios and $\Delta K$ baseline levels. In this study, the partial closure model, namely Eq. (4), established for constant amplitude loading, was used and enhanced to predict post-overload transients from far field closure measurements. It was showed, including for the crack growth rates and corresponding crack closure data presented in Figs. 10 and 11, respectively, that the plasticity-induced crack closure argument can fully explain the post-overload crack growth transients in alloy A when the phenomenon of partial closure is properly taken into account [17].

The disagreement observed between the crack closure transients for alloy B and the corresponding crack growth rate trend can be attributed to the high preoverload closure level observed for this alloy. It is important to note that this level is approximately equal to the maximum closure level induced by the overload applied in alloy $\mathrm{A}(U \approx 0.4)$. Thus, it is suggested that for alloys $\mathrm{B}$ and $\mathrm{C}$, the overload cycle induces crack tip blunting, which tends to decrease roughness-induced closure by reducing asperity contact. Additionally, the increase in plasticity-induced closure due to the overload plastic zone is not able to compensate this reduction and, consequently, the crack growth rate increases after the initial retardation. Therefore, plasticity-induced closure, contrary to the observed for alloy $\mathrm{A}$ [17], is not the main mechanism responsible for the retardation phase in alloys B and C. In these alloys, other mechanisms must be active, namely, crack tip blunting [12] and/or strain hardening [13].

\section{Conclusions}

From the experimental study on fatigue crack growth behaviour in AlMgSi1-T6 alloys with different chemical composition under constant amplitude loading and single tensile overload conditions, the following concluding remarks can be drawn:

1. A moderate $R$-ratio and a strong material dependence effects on the fatigue crack growth were observed. These effects are related to the different closure levels.

2. The crack growth behaviour of AlMgSil-T6 aluminium alloys depends mainly on whether the dominant closure mechanism is plasticity-induced or roughness-induced. For alloys with higher $\mathrm{Cr}$ and $\mathrm{Mn}$ contents, roughness-induced closure tends to be dominant. The rich $\mathrm{Mn} / \mathrm{Cr}$ dispersoid particles promote planar slip and crack deflection resulting in a tortuous crack path, enhancing roughness-induced crack closure and, thus, decreasing crack growth rates.

3. The crack growth increment affected by the overload was lower in alloys exhibiting an increased amount of incoherent dispersoid particles. The higher preoverload crack closure level observed in these alloys, provided by roughness-induced closure, must explain the lower influence of the overload that promotes mainly plasticity-induced closure.

4. When roughness-induced closure is the prime preoverload closure mechanism, the retardation effect seems to be due to mechanisms other than plasticityinduced closure.

\section{Acknowledgements}

The authors would like to acknowledge POCTI programme, project $1999 / \mathrm{EME} / 32984$, for funding the work reported. 


\section{References}

[1] Elber W. Fatigue crack closure under cyclic tension. Eng Fract Mech 1970;2:37-45.

[2] Blom AF, Holm DK. An experimental and numerical study of fatigue crack closure. Eng Fract Mech 1985;22:997-1011.

[3] Elber W. The significance of fatigue crack closure. Damage tolerance in aircraft structures, ASTM STP 486. Philadelphia: American Society for Testing and Materials; 1971. p. 230-42.

[4] Stofanak RJ, Wertzberg RW, Miller G, Jeccard R, Donald K. On the cyclic behavior of cast and extruded aluminium alloys, part A: fatigue crack propagation. Eng Fract Mech 1983;17:527-39.

[5] Petit J, Mendez J. Some aspects of the influence of microstructure on fatigue resistance. In: Lutjering G, Nowack H, editors. Fatigue '96: Proceedings of the Sixth International Fatigue Congress, vol. I. Oxford: Pergamon; 1996. p. 15-26.

[6] Bergner F, Zouhar G. A new approach to the correlation between the coefficient and the exponent in the power law equation of fatigue crack growth. Int J Fatigue 2000;22:229-39.

[7] Bergner F, Zouhar G, Tempus G. The material-dependent variability of fatigue crack growth rates of aluminium alloys in the Paris regime. Int J Fatigue 2001;23:383-94.

[8] Scheffel R, Detert K. The influence of crack closure on the fatigue crack propagation in the aluminium alloy AlMgSil. In: Faria LO, editor. ECF5: Proceedings of the Fifth European Conference on Fracture, vol. II. UK: EMAS publications; 1984. p. $805-10$.

[9] Scheffel R, Detert K. Near threshold crack propagation and crack closure in $\mathrm{Al}-\mathrm{Mg}-\mathrm{Si}$ alloys with varying manganese concentration. In: Van Elst HC, Bakker A, editors. Fracture control of engineering structures. ECF6: Proceedings of the Sixth European Conference on Fracture, vol. III. UK: EMAS publications; 1986. p. 1511-21.

[10] Lee DH, Park JH, Nam SW. Enhancement of mechanical properties of $\mathrm{Al}-\mathrm{Mg}-\mathrm{Si}$ alloys by means of manganese dispersoids. Mater Sci Technol 1999;15:450-5.

[11] Shijve J, Broek D. The result of a test program based on a gust spectrum with variable amplitude loading. Aircraft Eng 1962;34:314-6.

[12] Christensen RH. Fatigue crack, fatigue damage and their detection. Metal fatigue. New York: McGraw-Hill; 1959.

[13] Jones RE. Fatigue crack growth retardation after single-cycle peak overload in Ti-6Al-4V titanium alloy. Eng Fract Mech 1973;5:585-604.

[14] Suresh S. Micromechanisms of fatigue crack growth retardation following overloads. Eng Fract Mech 1983;18:577-93.

[15] Nicoletto G. Fatigue crack-tip mechanics in 7075-T6 aluminium alloy from high-sensitivity displacement field measurements. Nonlinear fracture mechanics. ASTM STP 995, vol. I. Philadelphia: American Society for Testing and Materials; 1989. p. 415-32.

[16] Borrego LP, Ferreira JM, Costa JM. Fatigue crack growth and crack closure in an AlMgSi alloy. Fatigue Fract Eng Mater Struct 2001;24:255-66.

[17] Borrego LP, Ferreira JM, Pinho da Cruz JM, Costa JM. Evaluation of overload effects on fatigue crack growth and closure. Eng Fract Mech 2003;70:1379-97.

[18] ASTM E 647, Standard test method for measurements of fatigue crack growth rates. Annual book of ASTM standards, vol.
03.01. West Conshohocken: American Society for Testing and Materials; 2000. p. 591-630.

[19] Allison JE, Ku RC, Pompetzki MA. A comparison of measurement methods and numerical procedures for the experimental characterization of fatigue crack closure. In: Newman Jr. JC, Elber W, editors. Mechanics of fatigue crack closure, ASTM STP 982. Philadelphia: American Society for Testing and Materials; 1988. p. 171-85.

[20] Shercliff HR, Fleck NA. Effect of specimen geometry on fatigue crack growth in plane strain-I. Constant amplitude response. Fatigue Fract Eng Mater Struct 1990;13:287-96.

[21] Wang J, Shen YP, Wanlin G. Modelling the influence of strain hardening and plastic constraint on crack closure of arbitrarily thick CCT-specimens. Fatigue Fract Eng Mater Struct 1998;21:1389-401.

[22] Costa JDM, Ferreira JAM. Effect of stress ratio and specimen thickness on fatigue crack growth of CK45 steel. Theor Appl Fract Mech 1998;30:65-73.

[23] Guo W, Wang CH, Rose LRF. The influence of cross-sectional thickness on fatigue crack growth. Fatigue Fract Eng Mater Struct 1999;22:437-44.

[24] Kim JK, Shim DS. The variation in fatigue crack growth due to the thickness effect. Int J Fatigue 2000;22:611-8.

[25] James MR, Morris WL. Effect of fracture surface roughness on growth of short fatigue cracks. Met Trans 1983;14A:153-5.

[26] Shercliff HR, Fleck NA. Effect of specimen geometry on fatigue crack growth in plane strain-II. Overload response. Fatigue Fract Eng Mater Struct 1990;13:297-310.

[27] Shin CS, Hsu SH. On the mechanisms and behaviour of overload retardation in AISI 304 stainless steel. Int J Fatigue 1993;15:181-92.

[28] Fleck NA. Influence of stress state on crack growth retardation. In: Fong JT, Fields RJ, editors. Basic questions in fatigue. ASTM STP 924, vol. 1. Philadelphia: American Society for Testing and Materials; 1988. p. 157-83.

[29] Bhandarkar MD, Lisagor WB. Metallurgical characterization of the fracture of aluminum alloys. In: Strauss BM, Cullen WH, editors. Fractography in failure analysis, ASTM STP 645. Philadelphia: American Society for Testing and Materials; 1978. p. 176-209.

[30] Kerlins V, Phillips A. Modes of fracture. ASM handbook. Fractography, vol. 12. Materials Park (USA): ASM International; 1992. p. $12-71$.

[31] Paris PC, Tada H, Donald JK. Service load fatigue damage-a historical perspective. Int J Fatigue 1999;21(Suppl):S35-46.

[32] Donald K, Paris PC. An evaluation of $\Delta K_{\text {eff }}$ estimation procedures on 6061-T6 and 2024-T3 aluminium alloys. Int J Fatigue 1999;21(Suppl):S47-57.

[33] Vasudevan AK, Sadananda K, Louat N. A review of crack closure, fatigue crack threshold and related phenomena. Mater Sci Eng 1994;A188:1-22.

[34] Newman Jr. JC. Analysis of fatigue crack growth and closure near threshold conditions for large-crack behavior. In: Newman Jr. JC, Piascik RS, editors. Fatigue crack growth thresholds, endurance limits, and design, ASTM STP 1372. West Conshohocken: American Society for Testing and Materials; 1999. p. 1-25. 